\title{
Nottingham Prognostic Index in Triple-Negative Breast Cancer: a reliable prognostic tool?
}

\author{
André Albergaria', Sara Ricardo ${ }^{1,2}$, Fernanda Milanezi ${ }^{1}$, Vítor Carneiro ${ }^{3}$, Isabel Amendoeira ${ }^{4}$, Daniella Vieira ${ }^{5}$, \\ Jorge Cameselle-Teijeiro ${ }^{6}$ and Fernando Schmitt ${ }^{1,4^{*}}$
}

\begin{abstract}
Background: A breast cancer prognostic tool should ideally be applicable to all types of invasive breast lesions. A number of studies have shown histopathological grade to be an independent prognostic factor in breast cancer, adding prognostic power to nodal stage and tumour size. The Nottingham Prognostic Index has been shown to accurately predict patient outcome in stratified groups with a follow-up period of 15 years after primary diagnosis of breast cancer. Clinically, breast tumours that lack the expression of Oestrogen Receptor, Progesterone Receptor and Human Epidermal growth factor Receptor 2 (HER2) are identified as presenting a "triple-negative" phenotype or as triple-negative breast cancers. These poor outcome tumours represent an easily recognisable prognostic group of breast cancer with aggressive behaviour that currently lack the benefit of available systemic therapy. There are conflicting results on the prevalence of lymph node metastasis at the time of diagnosis in triple-negative breast cancer patients but it is currently accepted that triple-negative breast cancer does not metastasize to axillary nodes and bones as frequently as the non-triple-negative carcinomas, favouring instead, a preferentially haematogenous spread. Hypothetically, this particular tumour dissemination pattern would impair the reliability of using Nottingham Prognostic Index as a tool for triple-negative breast cancer prognostication.

Methods: The present study tested the effectiveness of the Nottingham Prognostic Index in stratifying breast cancer patients of different subtypes with special emphasis in a triple-negative breast cancer patient subset versus non- triple-negative breast cancer.

Results: We demonstrated that besides the fact that TNBC disseminate to axillary lymph nodes as frequently as luminal or HER2 tumours, we also showed that TNBC are larger in size compared with other subtypes and almost all grade 3. Additionally, survival curves demonstrated that these prognostic factors are equally important to stratify different survival outcomes in non-TNBC as in TNBC. We also showed that the NPI retains the ability to stratify and predict survival of TNBC patients.
\end{abstract}

Conclusion: The importance of this study relies on the need of prognostication improvements on TNBC, showing, at a clinical standpoint, that Nottingham Prognostic Index is as a truthful prognostic tool in TNBC.

\section{Background}

Breast cancer comprises a complex and heterogeneous group of diseases at clinical, morphological and molecular levels [1-3]. It is clear that breast tumours of the same histological type show remarkably different clinical behaviour, which is probably a reflex of their distinct pattern of molecular aberrations [1,4]. Microarray technology has changed the way we understand breast

\footnotetext{
* Correspondence: fschmitt@ipatimup.pt

${ }^{1}$ Institute of Molecular Pathology and Immunology of Porto University (IPATIMUP), Porto, Portugal

Full list of author information is available at the end of the article
}

cancer classification by looking towards a molecularbased approach instead the traditional morphology and histopathological-based system [5,6]. Pioneered by the Stanford group [6-9] and lately explored by several other groups, a new taxonomy for breast cancer based on expression profile has claimed that the morphological heterogeneity of breast cancer can be recapitulated and systematically classified at the transcriptomic level and into clinically meaningful groups [10-12]. Such studies have shown that the molecular profile of breast cancer present a systematic variation which allowed its differential identification into two distinct branches [11],

\section{Biomed Central}


the ER-positive branch, comprising the luminal A and B subtypes, and three ER-negative branch, which comprises at least, two reproducible subtypes: the HER2overexpressing group and the basal-like group [6,8,9,13-15]. An additional group of tumours displaying molecular features of normal breast tissue, and therefore named as "normal-like", has been also included in this ER-negative branch. However, it has been suggested that this group represents an artefact with high contamination from normal breast tissue rather than a distinct molecular subtype [14]. Among the molecular subtypes of breast cancer identified through gene expression profiling studies, none has generated as much interest or controversy as the basal-like breast cancer group (BBC) [1]. Recently, a review published by a large group of renown breast pathologists and clinicians, advocated that there is still no internationally accepted definition for $\mathrm{BBC}$ and discussed how best to define these tumours [1]. Nevertheless, it is commonly accepted that the term "basal-like" reflects the similarity of the protein expression profile of these tumours with the one of basal epithelial cells of the normal mammary gland [16-19], including high-molecular-weight cytokeratins (CK) 5/6, 14 and CK17, vimentin, P-cadherin, caveolins- 1 and 2 , $\alpha B$-crystalin and fascin [8,20-29]. BBC, the only group consistently defined by gene expression arrays [30], account for up to $15 \%$ of all breast cancers $[1,11]$. These tumours frequently lack or show low levels of ER and PR, lack HER2 overexpression and amplification $[21,31,32]$ and in approximately $85 \%$ of the cases display p53 expression by immunohistochemistry or TP53 mutations [8,33]. Additionally, BBCs show exceedingly high levels of proliferation-related genes $[6,8,9,13]$ and express EGFR in a significant number of cases [21,34]. Defined by microarray-based expression profiling or by panels of immunohistochemical markers as surrogates, BBCs are known by their clinically aggressive behaviour $[8,10,21,32]$.

Specimens that display $\mathrm{BBC}$ features (hormone receptors and HER-2 lack of expression), are called, in routine practice, as "triple-negative" breast cancer (TNBC). Controversial and provocative data has been recently published questioning whether TNBC and $\mathrm{BBC}$ are synonymous. Because a majority of BBCs are also TNBCs and approximately $80 \%$ of TNBCs are also BBCs $[21,35]$, it has been claimed that the TNBC and BBC are effectively synonymous [36,37]. However, clinical, microarray and immunohistochemical data have shown that equating TNBC with BBC is misleading [15,33].

TNBC patients lack the benefit of routinely available target therapy, which explains the undeniable growing attention of both pathologists and oncologists as an easily recognisable group of breast cancer with aggressive behaviour and poor therapeutic options $[2,38]$. The prognosis of women with TNBC is significantly poor, compared to women with other subtypes of breast cancer. The higher recurrence and mortality rates of TNBC patients may be in part explained by different routes of metastatic spread [39]. There are conflicting results on the prevalence of lymph node metastasis at the time of diagnosis in TNBC patients [11]. Some studies described a higher prevalence of lymph node metastasis in TNBC [40], while others have found no statistical differences [3] or even an inverse association between TNBC and lymph node metastasis [41]. The currently accepted theory is that TNBCs seems to disseminate to axillary nodes and bones less frequently than the non-triplenegative cancers, presenting a preferential haematogenous route $[32,42-44]$ with a proclivity to develop metastatic deposits in the brain and lungs [11].

The Nottingham Prognostic Index (NPI) combines nodal status, tumour size and histological grade [45], reflecting metastatic behaviour, growth rate and genetic instability of breast cancers [46,47]. Most importantly, as a continuous variable, NPI offers a responsive and sensitive means of modelling a continuum of clinical aggressiveness [46], indexing the outcome likelihood of invasive breast cancer patients [48]. NPI can define 3 subsets of patients with different probabilities of dying from breast cancer; good $(\leq 3.4)$, moderate $(3.41-5.4)$, and poor (> 5.4) prognosis groups [48]. Three factors, found to be independently associated with survival on multivariate analysis, were combined to give the NPI algorithm. One of these factors is the lymph node stage, which has traditionally been regarded as the most powerful prognostic factor in breast cancer. The greater the number of nodes involved, the worse the prognosis [45].

As above mentioned, TNBCs are believed to infrequently disseminate to axillary lymph nodes in favour of distant and visceral metastatic spread $[32,39,42]$, an assumption that theoretically jeopardize the reliability of using NPI as a tool for TNBCs prognostication, since lymph nodal status is a major component for NPI calculation.

Herein, we investigated a large series of breast tumours and also a second cohort only composed by TNBC phenotype. These cohorts were used to test the clinical utility of NPI in predicting breast cancer patient outcome. Comparative analyses were performed within the TNBC subgroup of patients in order to evaluate the contribution of each Nottingham Prognostic components to the risk of worse survival and prognosis in TNBCs.

\section{Methods}

\section{Patient Selection}

A series of 467 primary invasive breast carcinomas diagnosed between 1978 and 1992 were retrieved from the Pathology Department, Hospital Xeral-Cíes, Vigo, Spain. 
Patients' ages ranged from 28 to 92 years old, mostly submitted to therapeutic surgery and/or surgery plus chemotherapy in the case of lymph node-positive patients. The formalin-fixed paraffin-embedded histological sections were reviewed and the diagnoses confirmed by two trained pathologists (FS and FM). The tumours were characterized for clinical and pathological parameters - namely age, tumour size, lymph-node status, and histological grade (Table 1). Whenever was possible, NPI was calculated for each of the patients by using the following equation: NPI $=0.2 \times$ tumour size $(\mathrm{cm})+$ grade $(1-3)+$ lymph node status (1-3) [47]. Patient follow-up information was available for 455 cases, ranging from a 1 to 120 months after the diagnosis. Overall and disease-free survival time was defined as the time from the date of surgery to the date of death or to the date of breast cancer derived relapse/metastasis, respectively.

An additional cohort of 168 TNBC patients was included in this study and analysed separately. This cohort resulted from the combination of the 89 triple negative tumours from the former series, plus 25 cases from the Divino Espirito Santo Hospital (Ponta Delgada-Portugal), 29 cases from the Federal University of Santa Catarina (Florianopolis-Brazil) and 25 cases from the São João Hospital (Porto-Portugal). All these TNBC specimens were evaluated and classified accordingly with the same criteria and by the same panel of pathologists. Patients followed the same therapeutic regimen design as the general series.

This study was conducted under the national regulative law for the handling of biological specimens from tumour banks, being the samples exclusively available for research purposes in retrospective studies.

\section{Tissue microarray construction and immunohistochemistry}

Representative tumour areas were selected on haematoxylin-eosin-stained sections. At least two tissue cores (0.6 $\mathrm{mm}$ in diameter) were obtained from each selected specimen and deposited into a recipient paraffin block, using a tissue microarray (TMA) workstation (Manual Tissue Arrayer, Beecher Instruments, Inc.). The TMA blocks were designed and built as previously described [20] and non-neoplastic tissue cores were included as controls.

In order to classify all breast cancer tumours according with the molecular subtype, immunohistochemistry was performed and the expression of breast cancer biomarkers [49], namely the hormonal receptors ER and PR, the tyrosine kinase receptors HER2 and EGFR, the basal cytokeratins CK5 and CK14, and also P-cadherin and vimentin were evaluated. Immunohistochemical expression was detected using HRP polymer (Cytomation
Table 1 Patients characteristics and tumour parameters

\begin{tabular}{|c|c|}
\hline Variable $(N=467)$ & Data \\
\hline \multicolumn{2}{|l|}{ Age at Diagnosis, years } \\
\hline Mean and standard deviation & $59 \pm 13$ \\
\hline Range & 64 (Min 28; Max 92) \\
\hline \multicolumn{2}{|l|}{ Tumour Size $(\mathrm{cm})$} \\
\hline Mean and standard deviation & $3.110 \mathrm{~cm} \pm 2.00 \mathrm{~cm}$ \\
\hline Range & $15.6(\operatorname{Min} 0.4 ; \max 16)$ \\
\hline $\mathrm{T} 1:<2 \mathrm{~cm}$ & $101(24.7 \%)$ \\
\hline $\mathrm{T} 2: 2-5 \mathrm{~cm}$ & 245 (59.9\%) \\
\hline T3: $>5 \mathrm{~cm}$ & $63(15.4 \%)$ \\
\hline Not assessed & 58 \\
\hline \multicolumn{2}{|l|}{ Lymph Node Invasion } \\
\hline Present & 207 (56.6\%) \\
\hline Absent & $159(43.4 \%)$ \\
\hline Not assessed & 101 \\
\hline \multicolumn{2}{|l|}{ Histological Grade } \\
\hline Grade I & $81(18.3 \%)$ \\
\hline Grade ॥ & 135 (30.5\%) \\
\hline Grade III & $227(51.2 \%)$ \\
\hline Not assessed & 24 \\
\hline \multicolumn{2}{|l|}{ Oestrogen receptor } \\
\hline Positive & $309(66.5 \%)$ \\
\hline Negative & $156(33.5 \%)$ \\
\hline Not assessed & 2 \\
\hline \multicolumn{2}{|l|}{ Progesterone Receptor } \\
\hline Positive & $228(48.9 \%)$ \\
\hline Negative & $238(51.1 \%)$ \\
\hline Not assessed & 1 \\
\hline \multicolumn{2}{|l|}{ HER2 } \\
\hline Positive & $68(14.7 \%)$ \\
\hline Negative & 395 (85.3\%) \\
\hline Not assessed & 4 \\
\hline \multicolumn{2}{|l|}{ Nottingham Prognostic Index } \\
\hline $\mathrm{NPI}<3.4$ & 99 (24.4\%) \\
\hline $3.4 \leq \mathrm{NPI} \leq 5.4$ & $188(46.4 \%)$ \\
\hline $\mathrm{NPI}>5.4$ & $118(29.2 \%)$ \\
\hline Not assessed & 62 \\
\hline \multicolumn{2}{|l|}{ Molecular Subtype } \\
\hline Luminal & $343(73.6 \%)$ \\
\hline HER2 Over-expressing & $33(7.1 \%)$ \\
\hline Triple Negative & 90 (19.3\%) \\
\hline
\end{tabular}

Envision System HRP, DAKO, Carpinteria, CA), according with the manufacturer's instructions. Both methods used diaminobenzidine as chromogen.

\section{Immunohistochemical evaluation}

The expression of ER, PR, HER2, EGFR, CK5, CK14, Pcadherin and vimentin was evaluated according with the grading systems previously described [49]. These immunohistochemical results were used to classify the 
tumours into the different breast cancer subtypes, namely Luminal, HER2-OE and Triple-negative (TNBC).

\section{Statistical analysis}

Statistical analysis was performed using SPSS statistics 17.0 software (SPSS Inc., Chicago, IL, USA). Continuous variables were presented as the mean standard deviation, and categorical variables were presented as number (percentage). Mean differences for continuous variables such as tumour size was performed using unpaired Ttest with a 95\% confidence interval. Association between different expression subtypes and the clinicopathological features were assessed by Pearson correlation and chisquared tests.

Survival curves were estimated by the Kaplan-Meier method using the long-rank test to assess significant differences in survival. Cox regression models were fitted to estimate hazard ratios [(HR, 95\% confidence interval $(\mathrm{CI}))]$ for the classical prognostic factors that constitute the Nottingham Prognostic Index, namely, tumour size, tumour grade and lymph-node status (LNS). Similarly, Cox regression was used to calculate HR for the NPI scoring in different expression subtypes. For all analysis, a significant level of $5 \%$ was considered.

\section{Results}

NPI as a predictor of survival in breast cancer subtypes

Using the follow-up survival data from 455 breast cancer patients, we stratified the breast-cancer-specific outcome, according with the NPI status. The NPI ranged from 2-8.4 (mean 4.8). In the whole series, and in line with what has been shown, NPI was able to stratify breast cancer patients into good, moderate and worse prognosis in terms of overall and disease-free survival (Figure 1A and 1B, respectively). The outcome stratification ability of NPI was also tested in specific breast cancer expression profiles. The same strength of statistical significance was also observed in the subset of luminal tumours (Figure $1 \mathrm{C}$ and $1 \mathrm{D}$ ). An interesting finding was the one observed in the HER2-OE subgroup, where none of the cases was scored as NPI $<3.4$, reinforcing the poor prognosis of this breast cancer subtype. Here, although the Kaplan-Meier curves showed a clear difference between the survival of NPI $>5.4$ and $3.4<\mathrm{NPI}<$ 5.4 patients, especially concerning overall-survival, the statistical value was not significant (Figure $1 \mathrm{E}$ and $1 \mathrm{~F}$ ). In the cohort of TNBC, unequivocal patient outcome stratification was draw by the NPI status. Notably, only one case was scored with NPI $<3.4$, confirming the aggressive behaviour pattern of these tumours. In fact, in both overall and disease-free survival Kaplan-Meier curves (Figure $1 \mathrm{G}$ and $1 \mathrm{H}$ ), TNBC patients with NPI > 5.4 are clearly separated from the good/moderate outcome curve, reinforcing not only the worse survival of the high-scored-NPI TNBC patients, but also suggesting the value of NPI as a predictor of survival in TNBC patients.

\section{Tumour size, histological grade and LNS in Luminal, HER2-OE and TN breast cancer}

Each clinical-pathological feature that constitutes the NPI equation was explored in the context of luminal, HER2-OE and TNBC groups. The mean tumour size was calculated for the three breast cancer subgroups. As shown in Table 2 the mean tumour size of TNBC was visibly higher compared to the average size of HER2-OE and luminal tumours, which displayed the lowest mean size. Using unpaired comparison analysis (T-test, 95\% $\mathrm{CI}$ ), to evaluate the significance of the difference found in tumour size between TNBC and each of the other subtypes, we showed that tumour size of TNBC was statistically different from the luminal subtype $(\mathrm{p}<0.001)$ and from the HER2-OE subtype $(\mathrm{p}=0.05)$. Concerning histological grade, Chi-square test showed that there was a significant association between grade and the different molecular subtypes $(\mathrm{p}<0.0001)$. The Table 2 shows that $78 \%$ and $71 \%$ of the HER2-OE and TNBC patients, respectively, were high-grade tumours, while the frequency distribution of tumour grade among luminal subtype tumours was rather homogeneous. Interestingly, a non-statistically significant association between LNS and the different expression subtypes was observed, showing that the occurrence of lymph-node metastization is a similarly frequent event across all the molecular subtypes, but most importantly, that the extension of these lymph-node involvement is as relevant in TNBC tumours $(26.4 \%)$ as it is for luminal $(29.4 \%)$ or HER2OE breast cancers (33.3\%) (Table 2).

\section{High-scored-NPI lesions and its relation with tumour size,} grade and LNS in a subset of TNBC

Using only the cohort of 164 TNBC patients, we evaluated the association of each of the Nottingham Prognostic components to the NPI augmentation. A boxplot graphic (Additional file 1) was draw to show the significant association of tumour size, histological grade and lymph node status to high scores of NPI in TNBC. Using Chi-square test we observed a strong association between larger tumours $(\mathrm{p}<0.0001)$, displaying high histological grade $(\mathrm{p}<0.0001)$ and with extensive lymph node invasion $(\mathrm{p}<0.0001)$, with the worst outcome group, represented by NPI $>5.4$ (Additional file 1). Besides the evidence that nearly $72 \%$ of TNBC are grade III tumours, therefore clearly contributing for a high NPI, it is however important to stress that the contribution of LNS also clearly associates with high NPI. Moreover, similarly with what was shown for tumour larger than $5 \mathrm{~cm}$, all the TNBC with more than 3 metastatic 

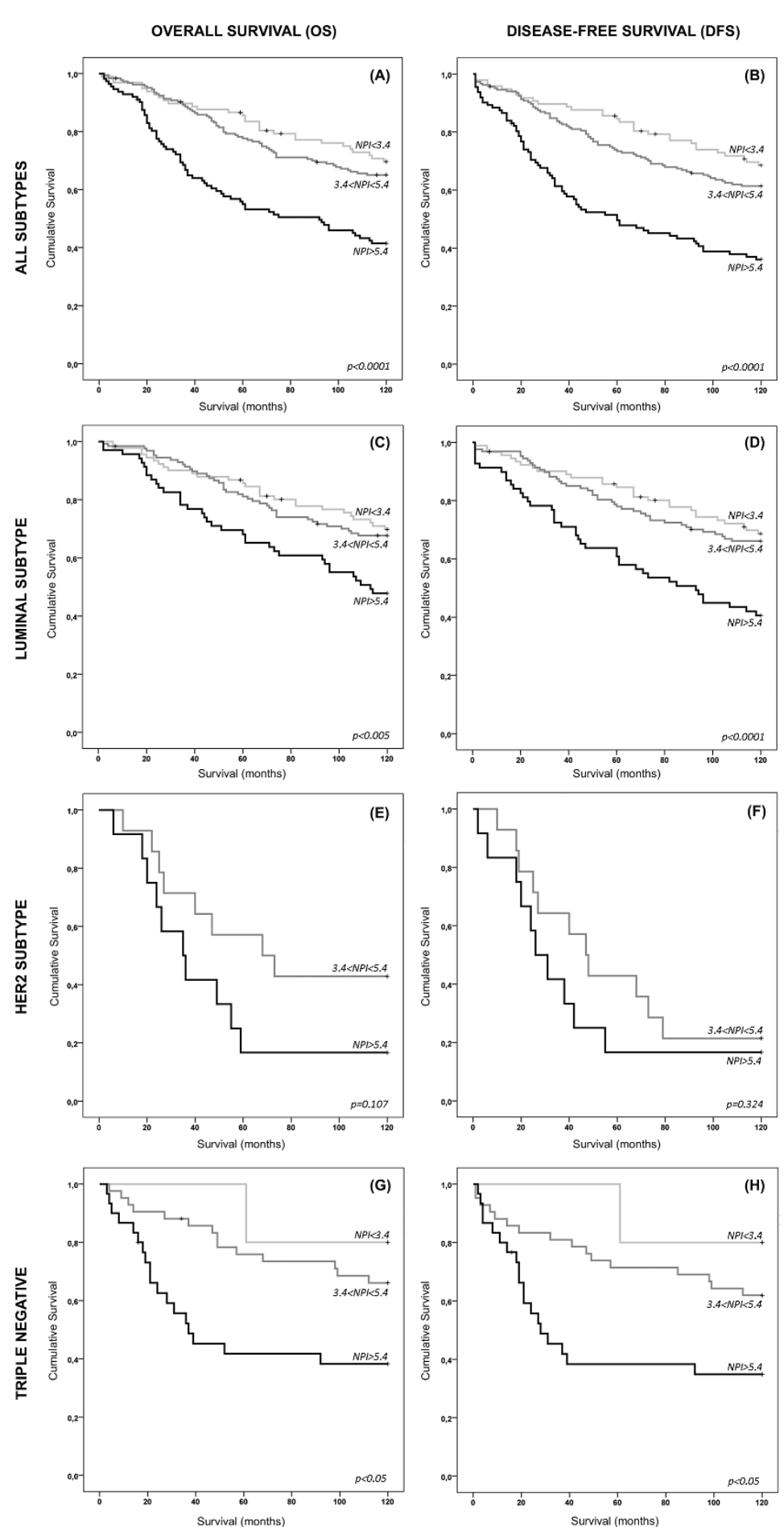

Figure 1 Long term overall and disease-free survival in breast cancer subtypes according with Nottingham Prognostic Index. KaplanMeier plots for a general series comprising all subtypes of invasive breast tumours (A and B). As expected, NPI clearly separate different groups with distinct outcomes, showing that patients with NPI > 5.4 presented a much worse prognosis compared with patients with moderate and good prognosis; (C and D) Kaplan-Meier plots for luminal subtype breast carcinomas. NPI is similarly able to stratify breast cancer patient into different survival outcomes; (E and F) Kaplan-Meier plots for HER2 subtype breast carcinomas. None of the patients encompassing this subgroup presented a NPI < 3.4. Although lacking statistical association, NPI is still able to discriminate between moderate and poor prognosis patients; (G and $\mathbf{H}$ ) Kaplan-Meier survival plots for TNBC subtype. Most of the patients within this subtype fell into the group with NPI > 5.4. Even though, NPI had the statistically significant power to stratify patients with distinct outcomes. 
Table 2 Nottingham Prognostic Index components on triple-negative and non-triple-negative breast cancer subtypes

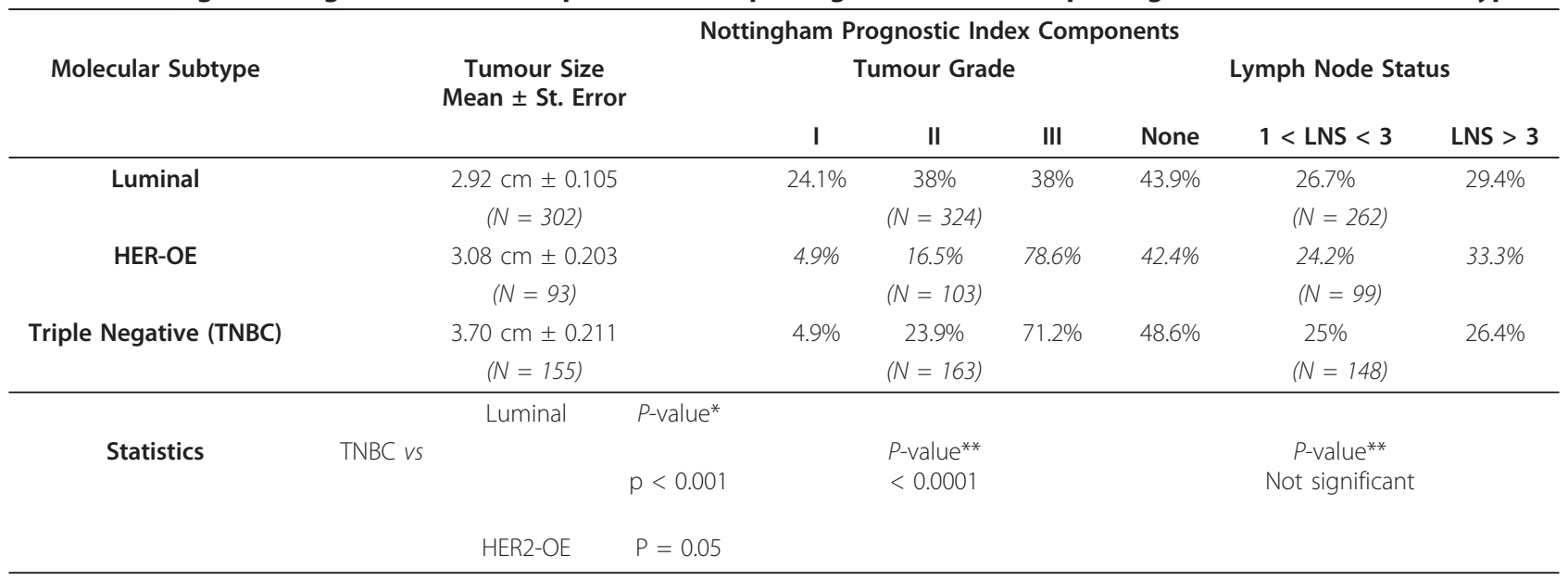

*ANOVA was used to compare the means of the three groups

** $P$-values were calculated with the use of the $\chi^{2}$ test

lymph nodes presented a NPI > 5.4 (Additional file 1), showing that LNS is a determinant factor to predict worse prognosis in TNBC patients.

Tumour size is theoretically associated with the increased likelihood of lymph node invasion in breast cancer. In fact, we demonstrated that in non-TNBC there was a strong association $(\mathrm{p}<0.0001)$ between tumour size and LNS, where $47 \%$ of patients with tumours larger than $5 \mathrm{~cm}$ presented extensive metastization (Table 3). In TNBC patients, $44 \%$ of patients with larger tumours also showed a significant trend $(\mathrm{p}<$ 0.001 ) to display more extensive lymph node invasion (Table 3). An additional analysis was also performed considering the presence or absence of lymph nodes involved, and herein, we observed that $61 \%$ of TNBCs with sizes $<2 \mathrm{~cm}$ lacked lymph node involvement, whereas approximately $78 \%$ of TNBCs with sizes $>5 \mathrm{~cm}$ displayed axillary lymph node invasion. These results showed that larger tumours frequently metastasize to lymph nodes, either being non-triple negative or TNBC lesions.
Significance of NPI components to breast cancer survival and mortality risk in TNBC patients

To evaluate the relevance of each NPI component to the survival of TNBC patients we used the follow-up data available for the TNBC cohort and survival curves were estimated by the Kaplan-Meier method. Survival curves demonstrated that TNBC patients with larger breast tumours showed a significant difference towards worse survival time ( $p<0.0001$; Figure $2 A$ ). Similarly, TNBC patient survival is seriously affected by the lymph node status ( $\mathrm{p}<0.0001$; Figure 2B).

As previously demonstrated by univariate hazard analysis [50], we also showed that tumour size, histological grade and lymph node status were significant predictors of overall survival in breast cancer series. The same Cox proportional analysis was used to estimate the risk associated to the survival difference found by Kaplan-Meier curves in TNBC cohort. We observed that tumour size was a significant predictor of survival in this subset of tumours, showing that patients with larger tumours carry about 3.2-fold-increased risk of breast cancer-

Table 3 Association of tumour size and lymph node status in triple-negative and non-triple-negative breast cancer

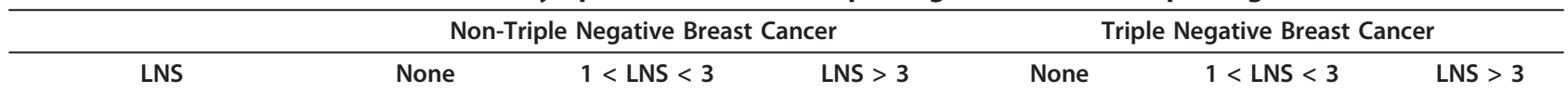

TS

\begin{tabular}{|c|c|c|c|c|c|c|}
\hline Tumour Size $<2 \mathrm{~cm}$ & $66.7 \%$ & $22.7 \%$ & $10.7 \%$ & $60.8 \%$ & $32.1 \%$ & $7.1 \%$ \\
\hline Tumour Size $2-5 \mathrm{~cm}$ & $39.4 \%$ & $26.1 \%$ & $34.5 \%$ & $56.7 \%$ & $19.8 \%$ & $23.5 \%$ \\
\hline Tumour Size $>5 \mathrm{~cm}$ & $19.4 \%$ & $33.3 \%$ & $47.2 \%$ & $22.2 \%$ & $33.3 \%$ & $44.5 \%$ \\
\hline Statistics & $(N=276)$ & & & $(N=145)$ & & \\
\hline
\end{tabular}



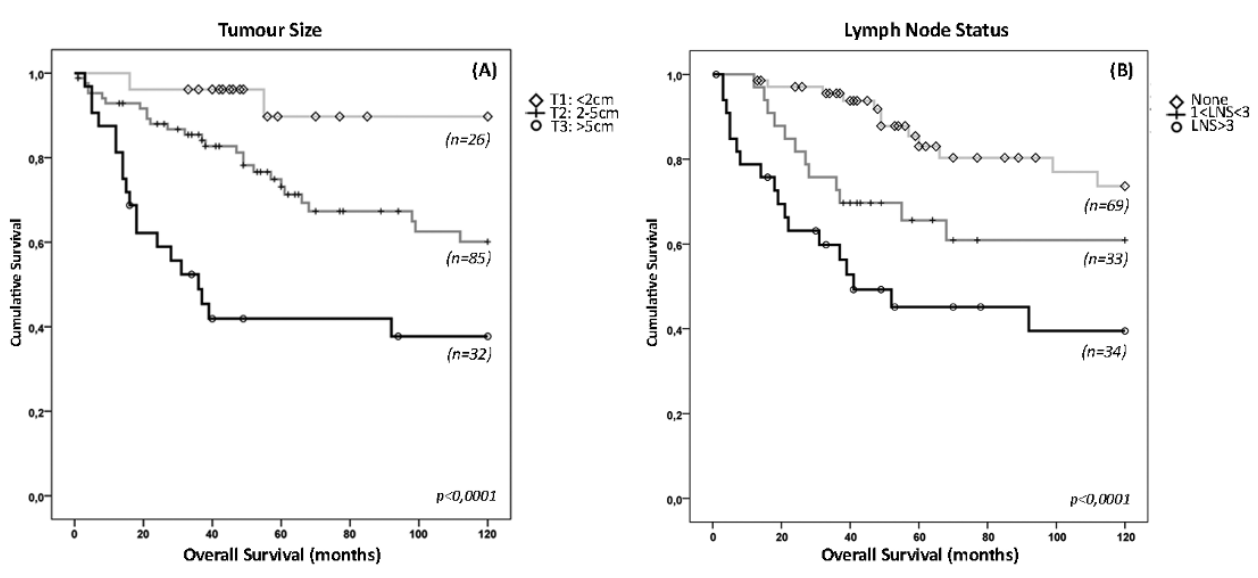

(c)

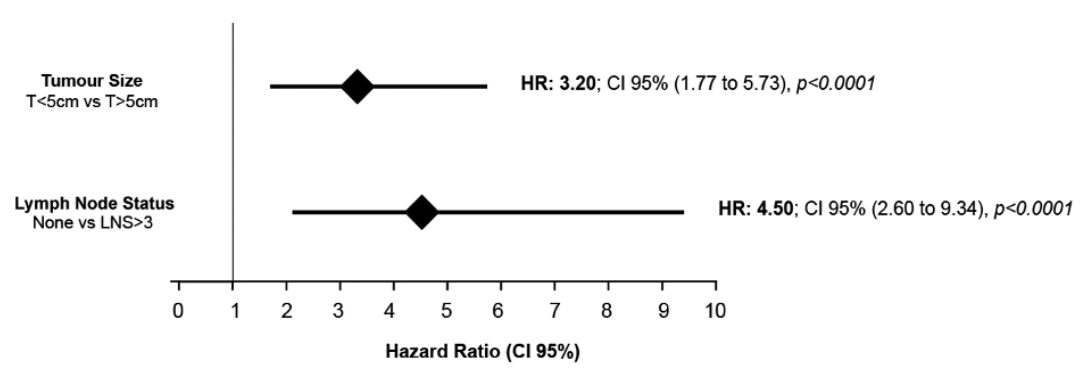

Figure 2 Significance of the NPI components to breast cancer mortality risk and survival in TNBC patients. Kaplan-Meier survival curves for tumour size (A) and for lymph node status (B). Both NPI components are highly statistically relevant to predict long term survival in TNBC patients; (C) Hazard ratio (Cl 95\%) in the TNBC cohort was calculated for tumour size and lymph node status. Patients with triple-negative tumours larger than $5 \mathrm{~cm}$ display a 3.2-fold risk of death by breast cancer; Concerning axillary lymph node status, TNBC patients with lymphatic involvement higher than 3 nodes have a 4.5 -fold risk of breast-cancer specific death.

related death ( $\mathrm{HR}=3.20,95 \% \mathrm{CI}: 1.77$ to 5.73$)$, compared to breast cancer patients with tumours smaller than $5 \mathrm{~cm}$ (Figure 2C). Notably, when risk analysis were applied to lymph node status, we observed that TNBC patients with more extensive lymph node invasion, hold approximately 4.5 -fold-increased risk of breast-cancerrelated death ( $\mathrm{HR}=4.50,95 \% \mathrm{CI}: 2.16$ to 9.34$)$, compared to patients lacking axillary invasion (Figure 2C).

\section{Discussion}

The prognosis of women with TNBC is significantly poor, compared to women with other subtypes of breast cancer. The underlying difference in recurrence and patient mortality rates may be explained in part by different routes of metastatic spread [51]. The current theory point out to the suggestion that TNBCs metastasize to axillary nodes and bones less frequently than the non-triple-negative subset of breast tumours, favouring a haematogenous spread [32,42-44].

In terms of survival, it has been described that the survival curve shape for TNBC or BBC differs from that of patients with other types of breast cancer: there is a sharp decrease in survival during the first 3 to 5 years after diagnosis, but distant relapse after this time is much less common $[31,40,41,52]$. In a study published by Dent and colleagues, the median time to death was 3.5 years for TNBC compared to 5.7 years for patients with other cancers [39]. In fact, as we can infer by the survival functions, TNBC experienced a severe decrease in their outcome before 48 months, a curve shape that overlaps with the one draw by the NPI in those patients. These findings reinforce the reliability of NPI as a tool to be reproducibly used in TNBC tumours.

In our cohort of TNBC we have found that tumour size is considerably higher compared with other subtypes of breast cancer. This difference in tumours size was strongly significant in relation to luminal, but not so marked when compared with HER2 tumours. Additionally, we found that, histologically, most TNBCs were high grade tumours. These results concerning tumour size and grade are largely in accordance with previous studies where these prognostic factors were studied within breast cancer subtypes, with special emphasis on TNBC versus non-TNBC patients $[40,50,53,54]$. One of these studies used a notably large series of TNBC $(6.370$ patients) and non-TNBC (44.704 patients), and similar 
findings concerning histological grade and tumour size were found [53]. Interestingly, we found no difference regarding lymph node metastization between luminal, HER2-overexpressing tumours and TNBC. Thus, although it has been suggested that TNBC tend to disseminate in a lower frequency to lymph nodes, we found that $51.4 \%$ of TNBC developed metastasis to lymph nodes. This percentage shows that 1 ) the lymph node involvement in TNBC is as frequent as in other subtypes of breast cancer and, 2) the extension of this involvement do not differ between breast tumour subtypes. In the last 4 years, interesting studies have reported data concerning positive lymph node status in TNBC compared to non-TNBC, describing percentages of positive lymph nodes in TNBC ranging from $42.5 \%$ [55] to $54.4 \%$ [40], therefore, corroborating the results presented herein. Based on that, and even considering some putatively less prominent lymph node involvement in TNBC, which accordingly to our results was not observed, tumour size and grade variables are someway playing a compensatory score augmentation to NPI algorithm. Additionally, survival curves concerning tumour size and lymph node status demonstrated that these prognostic factors are equally important to stratify survival outcomes in non-TNBC as in TNBC. Taken together, and considering that the majority of TNBC lesions are grade III, these largely studied prognostic factors are reliable to be used in the assessment of NPI in TNBC. Interestingly, we also found a slight association between tumour size and lymph node status in TNBC. This result contributes to some controversy concerning the existence or not of a relationship between size and lymph node status, since some authors already argued a lack of association between these two prognostic factors in TNBC [40]. In our TNBC series, we have a proportion of $74 \%$ of $\mathrm{BBC}$. The discrepancies about the association between tumour size and lymph node status could be explained if the TNBC cohort used by Dent et al. were enriched in basal-like breast tumours compared with the cohort we studied here. These hypothesis lay on a robust study recently published by Ellis group, where although a trend (non-significant) to display lymph node involvement with increasing tumour size was seen (especially in tumours larger than $4 \mathrm{~cm}$ ), basal-like tumours do not seem to obey the "size-node" rule [56].

\section{Conclusions}

While basal-like tumours is a designation only revealed by gene profiling signatures [6], TNBC is a clinicopathological classification which identifies a group of breast cancer with aggressive behaviour [2,38], and where improvements on therapy development and prognostication are compulsory. In the study presented herein, we demonstrated that besides the fact that TNBC disseminate to axillary lymph nodes as frequently as luminal or HER2 tumours, we also showed that TNBC are larger in size compared with other subtypes and almost all grade III, therefore making truthful, at a clinical standpoint, the applicability of NPI as a prognostic tool in TNBC.

\section{Additional material}

Additional file 1: Association of tumour size (A), histological grade (B) and lymph node status (C) to high scores of NPI in TNBC. The boxplot graphic show an association between larger tumours, displaying high histological grade and with extensive lymph node invasion, with tumours clustered into the worst outcome group, represented by NPI > $5.4(p<0.0001)(\mathbf{A}, \mathbf{B}$ and $\mathbf{C})$. The graphic highlights the contribution of lymph node status to the augmentation of NPI, showing that LNS is a determinant factor to predict worse prognosis in TNBC patients.

\section{Acknowledgements and Funding}

Authors would like to thank to Catarina Pereira by the effort and dedication in retrieving and organizing the breast cancer samples for this work. This work was supported by research grants from FCT - Foundation for Science and Technology [grant number SFRH/BPD/73247/2010 to A.A]. This work was also supported by a research project from Institute of Molecular Pathology and Immunology of Porto University (IPATIMUP), Porto, Portugal. IPATIMUP is an Associate Laboratory of the Portuguese Ministry of Science, Technology and Higher Education and is partially supported by FCT.

\section{Author details}

${ }^{1}$ Institute of Molecular Pathology and Immunology of Porto University (IPATIMUP), Porto, Portugal. ${ }^{2}$ Institute of Biomedical Sciences of Abel Salazar (ICBAS), Porto, Portugal. ${ }^{3}$ Department of Pathology of Hospital of Divino Espírito Santo, Ponta Delgada, Portugal. ${ }^{4}$ Department of Pathology, Medical Faculty of University of Porto, Alameda Prof. Hernâni Monteiro, Porto, Portugal. ${ }^{5}$ Federal University of Santa Catarina, Florianopolis, Brazil.

${ }^{6}$ Department of Pathology, Hospital Xeral-Cíes, Vigo, Spain.

\section{Authors' contributions}

AA carried out all the statistical studies, participated in the coordination of the study, intellectual content and drafted the manuscript. SR participated Pathologists VC, IA, DV, FM and JCT helped in the acquisition of data and evaluated the results of the clinic-pathological analysis. SR and FM were involved in critical revising and for important intellectual content. JCT and FS participate in the design of the study and coordination of the manuscript. All authors read and approved the manuscript.

\section{Competing interests}

The authors declare that they have no competing interests.

Received: 4 April 2011 Accepted: 15 July 2011 Published: 15 July 2011

\section{References}

1. Badve S, Dabbs DJ, Schnitt SJ, Baehner FL, Decker T, Eusebi V, Fox SB, Ichihara S, Jacquemier J, Lakhani SR, et al: Basal-like and triple-negative breast cancers: a critical review with an emphasis on the implications for pathologists and oncologists. Mod Pathol 2011, 24(2):157-167.

2. Rakha EA, Ellis IO: Triple-negative/basal-like breast cancer: review. Pathology 2009, 41(1):40-47

3. Rakha EA, El-Sayed ME, Green AR, Lee AH, Robertson JF, Ellis IO: Prognostic markers in triple-negative breast cancer. Cancer 2007, 109(1):25-32.

4. Weigelt B, Reis-Filho JS: Histological and molecular types of breast cancer: is there a unifying taxonomy? Nat Rev Clin Oncol 2009, 6(12):718-730 
5. Diaz LK, Cryns VL, Symmans WF, Sneige N: Triple negative breast carcinoma and the basal phenotype: from expression profiling to clinical practice. Adv Anat Pathol 2007, 14(6):419-430

6. Perou CM, Sorlie T, Eisen MB, van de Rijn M, Jeffrey SS, Rees CA, Pollack JR, Ross DT, Johnsen $H$, Akslen LA, et al: Molecular portraits of human breast tumours. Nature 2000, 406(6797):747-752

7. Perou CM, Jeffrey SS, van de Rijn M, Rees CA, Eisen MB, Ross DT, Pergamenschikov A, Williams CF, Zhu SX, Lee JC, et al: Distinctive gene expression patterns in human mammary epithelial cells and breast cancers. Proc Natl Acad Sci USA 1999, 96(16):9212-9217.

8. Sorlie T, Perou CM, Tibshirani R, Aas T, Geisler S, Johnsen H, Hastie T, Eisen $M B$, van de Rijn M, Jeffrey SS, et al: Gene expression patterns of breast carcinomas distinguish tumor subclasses with clinical implications. Proc Natl Acad Sci USA 2001, 98(19):10869-10874.

9. Sorlie T, Tibshirani R, Parker J, Hastie T, Marron JS, Nobel A, Deng S, Johnsen $\mathrm{H}$, Pesich R, Geisler S, et al: Repeated observation of breast tumor subtypes in independent gene expression data sets. Proc Natl Acad Sci USA 2003, 100(14):8418-8423.

10. Brenton JD, Carey LA, Ahmed AA, Caldas C: Molecular classification and molecular forecasting of breast cancer: ready for clinical application? J Clin Oncol 2005, 23(29):7350-7360

11. Reis-Filho JS, Tutt AN: Triple negative tumours: a critical review. Histopathology 2008, 52(1):108-118.

12. Reis-Filho JS, Westbury C, Pierga JY: The impact of expression profiling on prognostic and predictive testing in breast cancer. J Clin Pathol 2006 59(3):225-231

13. Hu Z, Fan C, Oh DS, Marron JS, He X, Qaqish BF, Livasy C, Carey LA Reynolds $E$, Dressler $L$, et al: The molecular portraits of breast tumors are conserved across microarray platforms. BMC Genomics 2006, 7:96.

14. Parker JS, Mullins M, Cheang MC, Leung S, Voduc D, Vickery T, Davies S, Fauron $C_{1}, \mathrm{He} X, \mathrm{Hu}$ Z, et al: Supervised risk predictor of breast cancer based on intrinsic subtypes. J Clin Oncol 2009, 27(8):1160-1167.

15. Rakha EA, Reis-Filho JS, Ellis IO: Basal-like breast cancer: a critical review. J Clin Oncol 2008, 26(15):2568-2581.

16. Gusterson BA, Ross DT, Heath VJ, Stein T: Basal cytokeratins and their relationship to the cellular origin and functional classification of breast cancer. Breast Cancer Res 2005, 7(4):143-148.

17. Jones C, Mackay A, Grigoriadis A, Cossu A, Reis-Filho JS, Fulford L, Dexter T, Davies S, Bulmer K, Ford E, et al: Expression profiling of purified normal human luminal and myoepithelial breast cells: identification of novel prognostic markers for breast cancer. Cancer Res 2004, 64(9):3037-3045.

18. Lakhani SR, O'Hare MJ: The mammary myoepithelial cell-Cinderella or ugly sister? Breast Cancer Res 2001, 3(1):1-4

19. Nofech-Mozes S, Trudeau M, Kahn HK, Dent R, Rawlinson E, Sun P Narod SA, Hanna WM: Patterns of recurrence in the basal and non-basal subtypes of triple-negative breast cancers. Breast Cancer Res Treat 2009, 118(1):131-137.

20. Matos I, Dufloth R, Alvarenga M, Zeferino LC, Schmitt F: p63, cytokeratin 5, and P-cadherin: three molecular markers to distinguish basal phenotype in breast carcinomas. Virchows Arch 2005, 447(4):688-694.

21. Nielsen TO, Hsu FD, Jensen K, Cheang M, Karaca G, Hu Z, HernandezBoussard T, Livasy C, Cowan D, Dressler L, et al: Immunohistochemical and clinical characterization of the basal-like subtype of invasive breast carcinoma. Clin Cancer Res 2004, 10(16):5367-5374.

22. Paredes J, Correia AL, Ribeiro AS, Albergaria A, Milanezi F, Schmitt FC: Pcadherin expression in breast cancer: a review. Breast Cancer Res 2007, 9(5):214..

23. Paredes J, Lopes N, Milanezi F, Schmitt FC: P-cadherin and cytokeratin 5: useful adjunct markers to distinguish basal-like ductal carcinomas in situ. Virchows Arch 2007, 450(1):73-80

24. Savage $K$, Lambros MB, Robertson $D$, Jones $R L$, Jones $C$, Mackay $A$ James $M$, Hornick JL, Pereira EM, Milanezi F, et al: Caveolin 1 is overexpressed and amplified in a subset of basal-like and metaplastic breast carcinomas: a morphologic, ultrastructural, immunohistochemical, and in situ hybridization analysis. Clin Cancer Res 2007, 13(1):90-101.

25. Savage K, Leung S, Todd SK, Brown LA, Jones RL, Robertson D, James M, Parry S, Rodrigues Pinilla SM, Huntsman D, et al: Distribution and significance of caveolin 2 expression in normal breast and invasive breast cancer: an immunofluorescence and immunohistochemical analysis. Breast Cancer Res Treat 2008, 110(2):245-256
26. Arnes JB, Brunet JS, Stefansson I, Begin LR, Wong N, Chappuis PO, Akslen LA, Foulkes WD: Placental cadherin and the basal epithelial phenotype of BRCA1-related breast cancer. Clin Cancer Res 2005, 11(11):4003-4011.

27. Sitterding SM, Wiseman WR, Schiller CL, Luan C, Chen F, Moyano JV Watkin WG, Wiley EL, Cryns VL, Diaz LK: AlphaB-crystallin: a novel marker of invasive basal-like and metaplastic breast carcinomas. Ann Diagn Pathol 2008, 12(1):33-40.

28. Paredes J, Albergaria A, Oliveira JT, Jeronimo C, Milanezi F, Schmitt FC: Pcadherin overexpression is an indicator of clinical outcome in invasive breast carcinomas and is associated with $\mathrm{CDH} 3$ promoter hypomethylation. Clin Cancer Res 2005, 11(16):5869-5877.

29. Albergaria A, Ribeiro AS, Pinho S, Milanezi F, Carneiro V, Sousa B, Sousa S, Oliveira C, Machado JC, Seruca R, et al: ICI 182,780 induces P-cadherin overexpression in breast cancer cells through chromatin remodelling at the promoter level: a role for C/EBPa in $\mathrm{CDH} 3$ gene activation. Hum Mol Genet 2010, 11(13):2554-2566

30. Weigelt B, Mackay A, A'Hern R, Natrajan R, Tan DS, Dowsett M, Ashworth A Reis-Filho JS: Breast cancer molecular profiling with single sample predictors: a retrospective analysis. Lancet Oncol 2010, 11:339-349.

31. Cheang MC, Voduc D, Bajdik C, Leung S, McKinney S, Chia SK, Perou CM, Nielsen TO: Basal-like breast cancer defined by five biomarkers has superior prognostic value than triple-negative phenotype. Clin Cancer Res 2008, 14(5):1368-1376.

32. Fulford LG, Reis-Filho JS, Ryder K, Jones C, Gillett CE, Hanby A, Easton D, Lakhani SR: Basal-like grade III invasive ductal carcinoma of the breast: patterns of metastasis and long-term survival. Breast Cancer Res 2007, 9(1):R4..

33. Rakha E, Ellis I, Reis-Filho J: Are triple-negative and basal-like breast cancer synonymous? Clin Cancer Res 2008, 14(2):618, author reply 618-619.

34. Reis-Filho JS, Milanezi F, Steele D, Savage K, Simpson PT, Nesland JM, Pereira EM, Lakhani SR, Schmitt FC: Metaplastic breast carcinomas are basal-like tumours. Histopathology 2006, 49(1):10-21.

35. Irvin WJ jr, Carey LA: What is triple-negative breast cancer? Eur J Cancer 2008, 44(18):2799-2805

36. Kreike $B$, van Kouwenhove $M$, Horlings $H$, Weigelt $B$, Peterse $H$, Bartelink $H$, van de Vijver MJ: Gene expression profiling and histopathological characterization of triple-negative/basal-like breast carcinomas. Breast Cancer Res 2007, 9(5):R65

37. Sotiriou C, Pusztai L: Gene-expression signatures in breast cancer. N Engl J Med 2009, 360(8):790-800.

38. Rakha EA, Elsheikh SE, Aleskandarany MA, Habashi HO, Green AR, Powe DG, El-Sayed ME, Benhasouna A, Brunet JS, Akslen LA, et al: Triple-negative breast cancer: distinguishing between basal and nonbasal subtypes. Clin Cancer Res 2009, 15(7):2302-2310.

39. Dent R, Hanna WM, Trudeau M, Rawlinson E, Sun P, Narod SA: Pattern of metastatic spread in triple-negative breast cancer. Breast Cancer Res Treat 2009, 115(2):423-428.

40. Dent R, Trudeau M, Pritchard KI, Hanna WM, Kahn HK, Sawka CA, Lickley LA Rawlinson E, Sun P, Narod SA: Triple-negative breast cancer: clinical features and patterns of recurrence. Clin Cancer Res 2007, 13(15):4429-4434.

41. Tischkowitz M, Brunet JS, Begin LR, Huntsman DG, Cheang MC, Akslen LA, Nielsen TO, Foulkes WD: Use of immunohistochemical markers can refine prognosis in triple negative breast cancer. BMC Cancer 2007, 7:134.

42. Hicks DG, Short SM, Prescott NL, Tarr SM, Coleman KA, Yoder BJ, Crowe JP, Choueiri TK, Dawson AE, Budd GT, et al: Breast cancers with brain metastases are more likely to be estrogen receptor negative, express the basal cytokeratin CK5/6, and overexpress HER2 or EGFR. Am J Surg Pathol 2006, 30(9):1097-1104

43. Rodriguez-Pinilla SM, Sarrio D, Honrado E, Hardisson D, Calero F, Benitez J, Palacios J: Prognostic significance of basal-like phenotype and fascin expression in node-negative invasive breast carcinomas. Clin Cancer Res 2006, 12(5):1533-1539.

44. Tsuda H, Takarabe T, Hasegawa T, Murata T, Hirohashi S: Myoepithelial differentiation in high-grade invasive ductal carcinomas with large central acellular zones. Hum Pathol 1999, 30(10):1134-1139.

45. Lee $\mathrm{AH}$, Ellis IO: The Nottingham prognostic index for invasive carcinoma of the breast. Pathol Oncol Res 2008, 14(2):113-115.

46. Miller DV, Leontovich AA, Lingle WL, Suman VJ, Mertens ML, Lillie J, Ingalls KA, Perez EA, Ingle JN, Couch FJ, et al: Utilizing Nottingham 
Prognostic Index in microarray gene expression profiling of breast carcinomas. Mod Pathol 2004, 17(7):756-764.

47. Galea MH, Blamey RW, Elston CE, Ellis IO: The Nottingham Prognostic Index in primary breast cancer. Breast Cancer Res Treat 1992, 22(3):207-219.

48. Kollias J, Murphy CA, Elston CW, Ellis IO, Robertson JF, Blamey RW: The prognosis of small primary breast cancers. Eur J Cancer 1999, 35(6):908-912.

49. Sousa B, Paredes J, Milanezi F, Lopes N, Martins D, Dufloth R, Vieira D, Albergaria A, Veronese L, Carneiro V, et al: P-cadherin, vimentin and CK14 for identification of basal-like phenotype in breast carcinomas: an immunohistochemical study. Histol Histopathol 2010, 25(8):963-974.

50. Yang XR, Sherman ME, Rimm DL, Lissowska J, Brinton LA, Peplonska B, Hewitt SM, Anderson WF, Szeszenia-Dabrowska N, Bardin-Mikolajczak A, et al: Differences in risk factors for breast cancer molecular subtypes in a population-based study. Cancer Epidemiol Biomarkers Prev 2007, 16(3):439-443.

51. Dent R, Hanna WM, Trudeau M, Rawlinson E, Sun P, Narod SA: Time to disease recurrence in basal-type breast cancers: effects of tumor size and lymph node status. Cancer 2009, 115(21):4917-4923.

52. Foulkes WD, Smith IE, Reis-Filho JS: Triple-negative breast cancer. N Engl J Med 2010, 363(20):1938-1948.

53. Bauer KR, Brown M, Cress RD, Parise CA, Caggiano V: Descriptive analysis of estrogen receptor (ER)-negative, progesterone receptor (PR)-negative, and HER2-negative invasive breast cancer, the so-called triple-negative phenotype: a population-based study from the California cancer Registry. Cancer 2007, 109(9):1721-1728.

54. Blows FM, Driver KE, Schmidt MK, Broeks A, van Leeuwen FE, Wesseling J, Cheang MC, Gelmon K, Nielsen TO, Blomqvist C, et al: Subtyping of breast cancer by immunohistochemistry to investigate a relationship between subtype and short and long term survival: a collaborative analysis of data for 10,159 cases from 12 studies. PLoS Med 2010, 7(5):e1000279.

55. Spitale A, Mazzola P, Soldini D, Mazzucchelli L, Bordoni A: Breast cancer classification according to immunohistochemical markers: clinicopathologic features and short-term survival analysis in a population-based study from the South of Switzerland. Ann Oncol 2009, 20(4):628-635.

56. Foulkes WD, Grainge MJ, Rakha EA, Green AR, Ellis IO: Tumor size is an unreliable predictor of prognosis in basal-like breast cancers and does not correlate closely with lymph node status. Breast Cancer Res Treat 2008, 117(1):199-204

\section{Pre-publication history}

The pre-publication history for this paper can be accessed here: http://www.biomedcentral.com/1471-2407/11/299/prepub

doi:10.1186/1471-2407-11-299

Cite this article as: Albergaria et al:: Nottingham Prognostic Index in Triple-Negative Breast Cancer: a reliable prognostic tool? BMC Cancer 2011 11:299.

\section{Submit your next manuscript to BioMed Central and take full advantage of:}

- Convenient online submission

- Thorough peer review

- No space constraints or color figure charges

- Immediate publication on acceptance

- Inclusion in PubMed, CAS, Scopus and Google Scholar

- Research which is freely available for redistribution 